\title{
Abrasive wear of WC-NiMoCrFeCo thermally sprayed coatings in dependence on different types of abrasive sands
}

\author{
M. Kašparová ${ }^{1 *}$, F. Zahálka ${ }^{1}, \overleftrightarrow{\text { S. Houdková }}{ }^{1}$, P. Ctibor $^{2}$ \\ ${ }^{1}$ Department of Thermal Spraying, SKKODA VÝZKUM Ltd., Tylova 1/57, 31600 Pilsen, Czech Republic \\ ${ }^{2}$ Institute of Plasma Physics, Academy of Science CR, Za Slovankou 3, 18200 Prague 8, Czech Republic
}

Received 16 March 2009, received in revised form 16 June 2009, accepted 19 October 2009

\begin{abstract}
The abrasive wear is a very extended type of wear, which in $80 \%-90 \%$ causes all possible damages of machine elements operation parts. WC-NiMoCrFeCo coating was investigated as an advantageous material for wear protection and its abrasion wear resistance was tested. The tribological tests were performed in "low-stress conditions" using Dry Sand Rubber/Wheel Test in accordance with the ASTM G-65 Standard. Alumina and silica abrasive sands were chosen in three different size distributions: $\mathrm{Al}_{2} \mathrm{O}_{3}$ in grain size $75-90 \mu \mathrm{m}, 212-250 \mu \mathrm{m}, 600$ $700 \mu \mathrm{m}$ and $\mathrm{SiO}_{2}$ in grain size 60-90 $\mu \mathrm{m}, 200-300 \mu \mathrm{m}, 600-700 \mu \mathrm{m}$. The wear tracks of WC-Hastelloy coating were examined using scanning electron microscope. WC-NiMoCrFeCo was found as a good alternative to the commonly used carbide coating. To evaluate an abrasive ability and efficiency of all abrasive mediums, the wear test of soft carbon steel and of WC-Hastelloy coating was performed by periodical using of abrasive particles.
\end{abstract}

Ke y words: WC-Hastelloy, abrasive wear, $\mathrm{Al}_{2} \mathrm{O}_{3}$ sand, $\mathrm{SiO}_{2}$ sand, grain size, abrasive efficiency

\section{Introduction}

Wear is a major problem in the earth moving, excavation, mining and minerals processing industries. The wear of parts, the cost of repair and the replacement of these parts result in significant costs to these industries. To prevent these negative effects it is necessary to find a wide scale of wear resistant materials. For investigations of material properties in different conditions the laboratory wear tests are carried out. The dry sand rubber/wheel abrasion test as described the ASTM Standard G-65 [1] is commonly used to evaluate the abrasive wear behaviour of materials under three-body conditions [2], which means that a smaller particle of the abrasive, caught between the two other surfaces and sufficiently harder that it is able to abrade either one or both of the mating surfaces. In the wear test, a plane specimen is loaded against the rim of a rotating rubber wheel, sand is fed into the gap between the wheel and the specimen and it is carried past the specimen and thus abrades it. The conditions in this test can be described as a "low stress scratching abrasion". The low-stress abrasion occurs when lightly loaded abrasive particles impinge on and move across the wearing surface, producing cutting and ploughing on a microscopic scale [3]. In aqueous or other liquid environments, corrosion may also contribute to the overall wear rate. In this case erosion-corrosion is the operative wear mechanism [4].

WC-based cermet coatings are noted for superior abrasive wear resistance, such as WC-Co, WC-Co-Cr, WC-Hastelloy, WC-Ni coatings, etc. WC-Hastelloy is in addition an innovative WC-based material with a highly corrosion resistant matrix based on Hastelloy C-type [5]. This powder has been specially developed for the deposition by the HVOF systems to produce coatings with superior corrosion resistance than WC- $\mathrm{Co}-\mathrm{Cr}$ coatings whilst retaining the wear resistance of the standard WC-coatings [6]. Nickel alloys contain significant quantities of chromium and molybdenum, along with the requisite minor elements to allow successful and economical melting. This processing can be age-hardened to provide a high strength and possess high resistance to uniform corrosion attack in both ox-

*Corresponding author: tel.: +420 379852 229; fax: +420 379852 217; e-mail address: $\underline{\text { michaela.kasparova@skodavyzkum.cz }}$ 
idizing and reducing media while in the age hardened condition; Ni-Cr-Mo (C-type) alloys are popular materials of construction throughout the chemical process industries and their primary attributes are high resistance to the halogen acids, in particular hydrochloric, and high resistance to chloride-induced corrosion phenomena, such as pitting, crevice attack and stress corrosion cracking [5]. The basic structure of the C-type alloys is a face-centred cubic, which is also the structure of nickel, a ductile and reasonably corrosion-resistant metal, in which large quantities of useful elements, such as chromium and molybdenum, are soluble; the primary function of chromium is to provide passivity in oxidizing acid solutions; molybdenum greatly enhances the resistance of nickel to reducing acids and increases the resistance to a localized attack (pitting and crevice corrosion) [5].

Due to great anti-corrosion properties of the Hastelloy C-types alloys, the WC-Hastelloy coating is a good alternative of some expensive stainless materials in addition with retaining the wear resistance. In this study, the abrasion wear resistance of the WC-Hastelloy coating to different types of abrasive sands was recognized.

\section{Experimental}

Table 1 shows the composition of the powder used. The WC-Hastelloy powder, escutcheon badge AMPERIT 529.074 or WC-NiMoCrFeCo 85/15, was produced by H. C. Starck using agglomerated and sintered process and sieved size distribution -45 $+15 \mu \mathrm{m}$. This powder was sprayed using the HVOF process. Carbon steel EN 10025-90 of the composition shown in Table 2 was used as a substrate.

HVOF spraying was carried out using the JP-5000 gun. Kerosene was used as a fuel gas. The spray parameters were optimised and after that used for all tested samples.

Metallographic investigation was carried out using the scanning electron microscopy. SEM provides a samples observing in different visual modes. The scanning electrons mode (SE) displays micrographs of the sample surface. The other SEM possibility is backscatters electrons mode (BSE) that displays elements (phases) according to their atomic weight. The micrograph is then formed by the grayscale. "The heavier" elements are depicted in a light colour and "the lighter" in dark, respectively. Chemical composition of the coating was evaluated using SEM via EDAX analysis and phase compositions were evaluated via X-ray diffraction. The microhardness of the coating (Vickers scale) was measured using the LECO DM-400A micro-hardness tester with load $300 \mathrm{~g}$ and dwell time $10 \mathrm{~s}$; the surface hardness of the coating (Rockwell's scale) was measured by the Amsler-Wolpert Tester HT 2003
Table 1. Chemical composition of the WC-Hastelloy powder

\begin{tabular}{ccccccccc}
\hline $\begin{array}{c}\text { Element } \\
\text { (wt.\%) }\end{array}$ & balance & 10.76 & 2.83 & 3.00 & 1.09 & 0.48 & 5.63 & 0.04 \\
\hline
\end{tabular}

Table 2. Chemical composition of the EN 10025-90 carbon steel

\begin{tabular}{cccccccc}
\hline $\begin{array}{c}\text { Element } \\
(\text { wt.\%) }\end{array}$ & $\mathrm{C}$ & $\mathrm{Mn}$ & $\mathrm{Si}$ & $\mathrm{P}$ & $\mathrm{S}$ & $\mathrm{N}$ & $\mathrm{Fe}$ \\
& 0.2 & 1.6 & 0.5 & 0.04 & 0.04 & 0.009 & balance \\
\hline
\end{tabular}

hardness tester and the surface roughness was measured by the SJ-201P surface roughness tester.

For the wear performance evaluation of the WC-Hastelloy coating and of the carbon steel the "Dry Sand Rubber/Wheel Test" was used. The basic principle of the test is described in [1]. Table 2 shows the chemical composition of the carbon steel (base strength characteristic: $R_{\mathrm{m}}=450-630 \mathrm{MPa}$, density $\left.7.8 \mathrm{~g} \mathrm{~cm}^{-3}\right)$. Two different abrasive sand particles in three different grain sizes were used for the wear test. After the wear test, the surface morphology of the WC-Hastelloy coating and of all abrasive particles was investigated by SEM. In the wear test "low-stress conditions" were chosen; it means the rubber rim of the wheel and $22 \mathrm{~N}$ samples load was used. For all tested samples the abrasion line of $1436 \mathrm{~m}$ divided to five cycles was chosen.

Further an abrasive efficiency of all abrasive sand particles was determined by their periodical using.

\section{Results and discussion}

\subsection{Powders and coatings characterization}

Figure 1a shows the SEM micrographs of the surface morphology of the WC-Hastelloy powder and Fig. 1b shows a powder cross-section. The particles of this agglomerated \& sintered powder are spherical and relatively porous. As can be derived from the different grey-scales, the powder is characterized by the appearance of at least two phases, which have in part inhomogeneous distributions. On the powder cross-section in Fig. 1b there is shown the classic hard metal composite, in which carbide particles are embedded in a metal-alloy binder matrix. This base composition, which means hard phase in a ductile binder phase, is typical for most of all WC-based carbides coatings [711]. In [12], the WC-Hastelloy agglomerated/sintered powder was also investigated using SEM and the mapping of different elements distribution $(\mathrm{W}, \mathrm{Ni}, \mathrm{Fe}, \mathrm{Cr}$, 

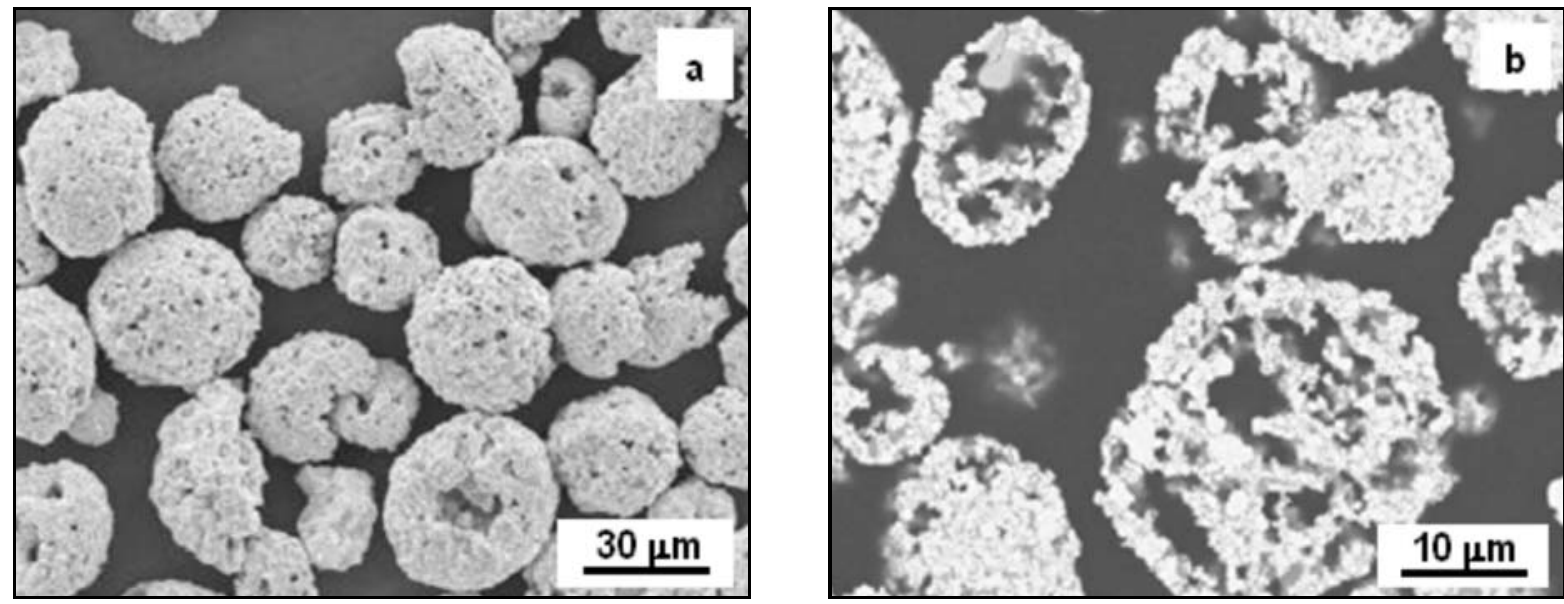

Fig. 1. SEM micrographs of the WC-Hastelloy powder [6]: a) surface morphology of the powder particles, b) cross-section of the powder particles.

Mo) was performed. Authors in [12] found that nickel and iron were homogenously distributed in the metal and that a strong signal from $\mathrm{Ni}$ was registered in the centre of the powder. The stronger signal for $\mathrm{Ni}$ was imputed to the explaining of the fact that $\mathrm{Ni}$ is the major constituent of the WC-Hastelloy-C alloy. The distribution of chromium and molybdenum was more interesting. Diffusion of chromium and molybdenum to the WC-rich part was found. This fact authors imputed to $\mathrm{Cr}$ and Mo reaction with carbon in the WC and to forming carbides during the sintered manufacturing phase.

Figure 2b,c,d shows the SEM micrographs of the cross-sections of coatings microstructure performed in three different magnifications. The WC-Hastelloy coating is obviously dense with small pores content. From this micrographs observation, the $\mathrm{WC}$ carbides are homogenously distributed in the metal matrix, Fig. 2c, and the coating adhesion to the substrate appears to be excellent, Fig. 2b.

Chemical composition of the coating was determined by the scanning electron microscope using the EDAX analysis. The results are shown in Table 3. In comparison, chemical elements content in the WC-Hastelloy is relatively identical for the initial powder material and final coating, see Table $1-\mathrm{H}$. C. Starck information about chemical composition of the powder. Only a higher amount of oxygen was detected in the coating as a result of liquid-metallic phase oxidation during the spraying process. The EDAX analysis was performed on the free surface, which as well could influence the results by coating surface oxidizing.

Figure 3 shows the X-ray diffraction pattern of the WC-Hastelloy coating. WC was identified as the main phase for the coating. The appearance of the type $\mathrm{A}_{2} \mathrm{~B}$ phase $\left(\mathrm{W}_{2} \mathrm{C}\right)$ can be explained by decarburization of WC. And next, the phase of the $\mathrm{M}_{6} \mathrm{C}$ carbide $\left(\mathrm{Co}_{6} \mathrm{Mo}_{6} \mathrm{C}\right)$ type was also detected in the coating. $\mathrm{Co}_{6} \mathrm{Mo}_{6} \mathrm{C}$ phase is distinguished as having a cu-
Table 3. Values from EDAX analysis of the WCHastelloy coating (wt.\%)

\begin{tabular}{lccccrcr}
\hline Spectrum & O & Cr & Fe & Co & Ni & Mo & W \\
\hline Average & 3.2 & 2.8 & 1.3 & 0.8 & 13.1 & 3.4 & 75.4 \\
St. dev. & 0.3 & 0.1 & 0.1 & 0.1 & 0.4 & 0.4 & 0.6 \\
Max. & 3.4 & 3.0 & 1.5 & 0.9 & 13.5 & 3.9 & 76.3 \\
Min. & 2.6 & 2.7 & 1.1 & 0.7 & 12.4 & 3.0 & 74.5 \\
\hline
\end{tabular}

bic crystal structure; $\mathrm{W}_{2} \mathrm{C}$ and $\mathrm{WC}$ have a hexagonal crystal structure.

\subsection{Mechanical properties of the coating}

In Table 4 there are summarized several main mechanical properties of the WC-Hastelloy coating. The microhardness $\left(\mathrm{HV}_{0.3}\right)$ data of the coating were measured 10 times and the average value was calculated. The microhardness of this cermet is relatively high due to high content of hard WC grains (85\% mass). The influence of $\mathrm{WC}$ content in cermet coatings on microhardness values is described in [13]. The WC-Hastelloy coatings were also investigated by authors in $[12,14]$. They used the JP-5000 and the DJ-2600 spray guns for spraying and measured relatively high microhardness for these types of coatings, about 1200 $\mathrm{HV}_{0.3}$. The coating microhardness of both spraying systems was in the same range. However, it is obvious that the microhardness and other mechanical properties, respectively, depend above all on the spraying parameters used in individual companies.

The coating roughness value mentioned in Table 4 has a typical value of all conventional HVOF sprayed cermet coatings in ŠKODA VYZKUM Ltd. Pilsen, CZ. This relatively high surface roughness confirms to the surface coating morphology, splats and carbides distribution, see Fig. 2a. The value of coatings density 

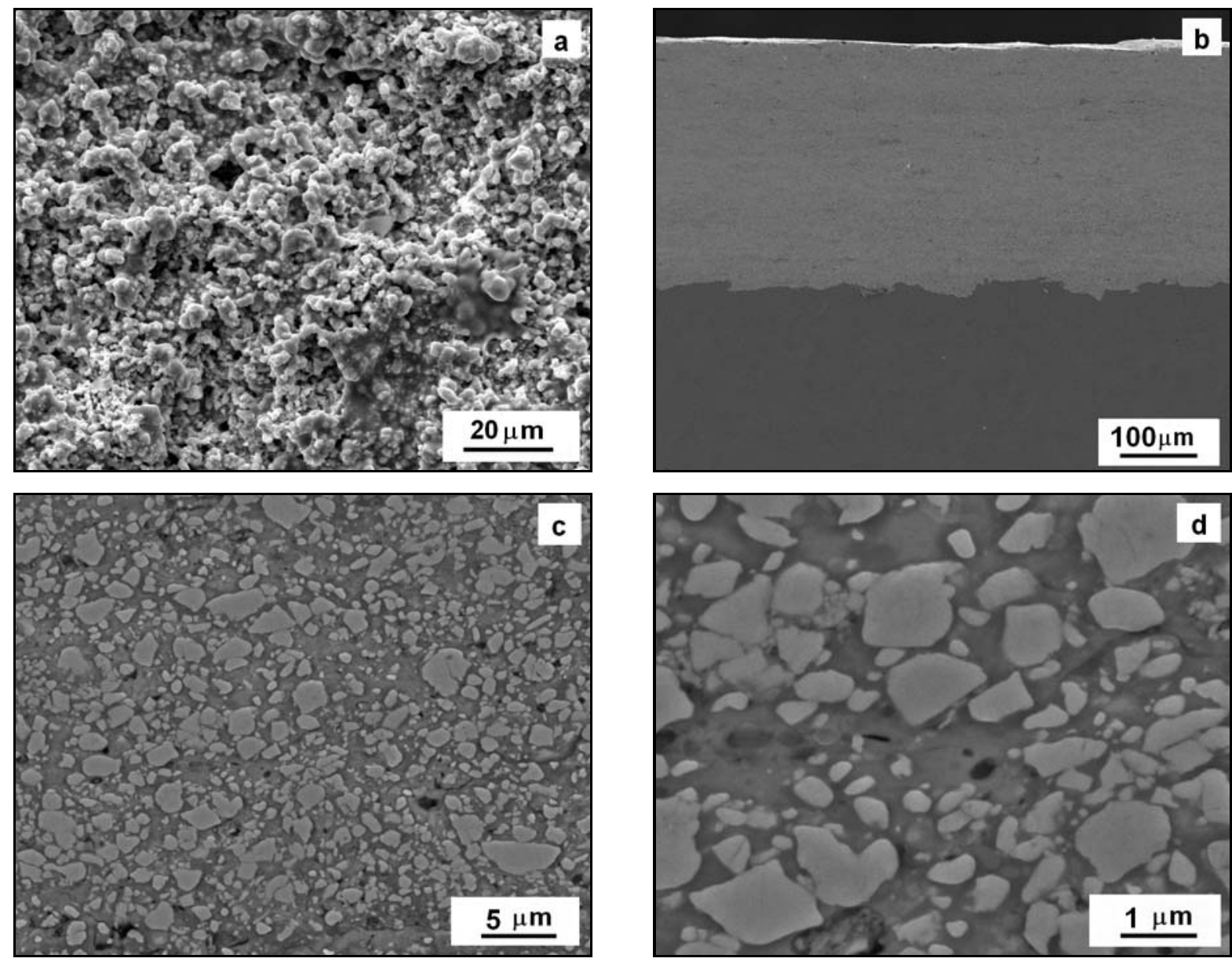

Fig. 2. SEM micrographs of the WC-Hastelloy coating: a) coatings surface morphology, b), c), d) coatings cross-sections.

Ta ble 4. Mechanical-physical properties of the coating

\begin{tabular}{ccccc}
\hline & Microhardness $\mathrm{HV}_{0.3}$ & $\begin{array}{c}\text { Surface hardness HR15N } \\
(\sim \mathrm{HRC})\end{array}$ & $\begin{array}{c}\text { Surface roughness } R_{\mathrm{a}} \\
(\mu \mathrm{m})\end{array}$ & $\begin{array}{c}\text { Coating density } \\
(\mathrm{g} \mathrm{cm})\end{array}$ \\
\cline { 2 - 5 } WC-Hastelloy & $986.5 \pm 68.9$ & $92.8 \pm 0.9(\sim 66.2)$ & $3.08 \pm 0.023$ & $13.256 \pm 0.1$ \\
\hline
\end{tabular}

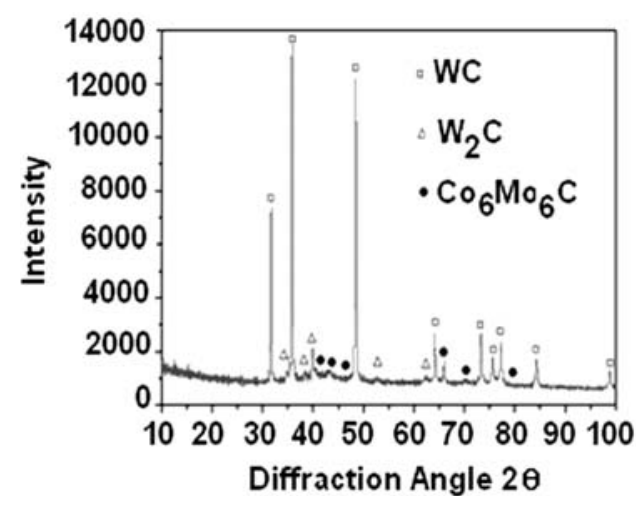

Fig. 3. X-ray diffractogram of the WC-Hastelloy coating. is similar to density values of other WC-based cermet coatings that are produced using the HVOF technology in ŠKODA VYZKUM Ltd. Pilsen, CZ.

\subsection{Abrasion wear resistance}

The wear occurs if a harder part damages the other softer one. In such a case the wear of the soft material occurs and then the harder part can be called wear medium. In case of abrasive wear the abrasive particles that affect the surface of abraded material or coating cause the wear. A large scale of different types of abrasive mediums with different properties (shape, size, hardness...) exists which significantly influence the surfaces of machine parts in different branches of 

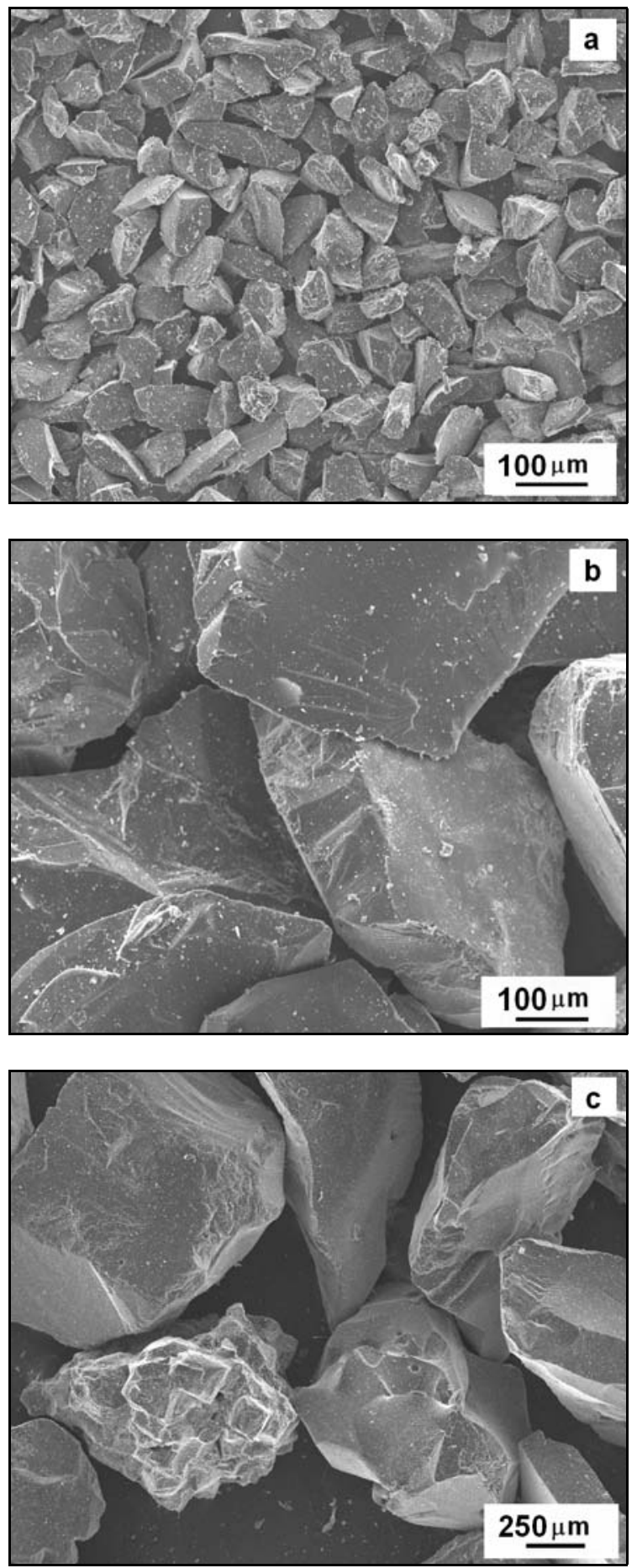

Fig. 4. SEM micrographs of the $\mathrm{Al}_{2} \mathrm{O}_{3}$ sands surface morphology: a) $75-90 \mu \mathrm{m}$ grain size, b) $212-250 \mu \mathrm{m}$ grain size, c) $600-700 \mu \mathrm{m}$ grain size.

industry. In our study, two different types of abrasive particles were chosen, one kind of very hard and aggressive $\mathrm{Al}_{2} \mathrm{O}_{3}$ sand particles in three grain sizes and one kind of softer $\mathrm{SiO}_{2}$ sand particles in identical grain sizes.
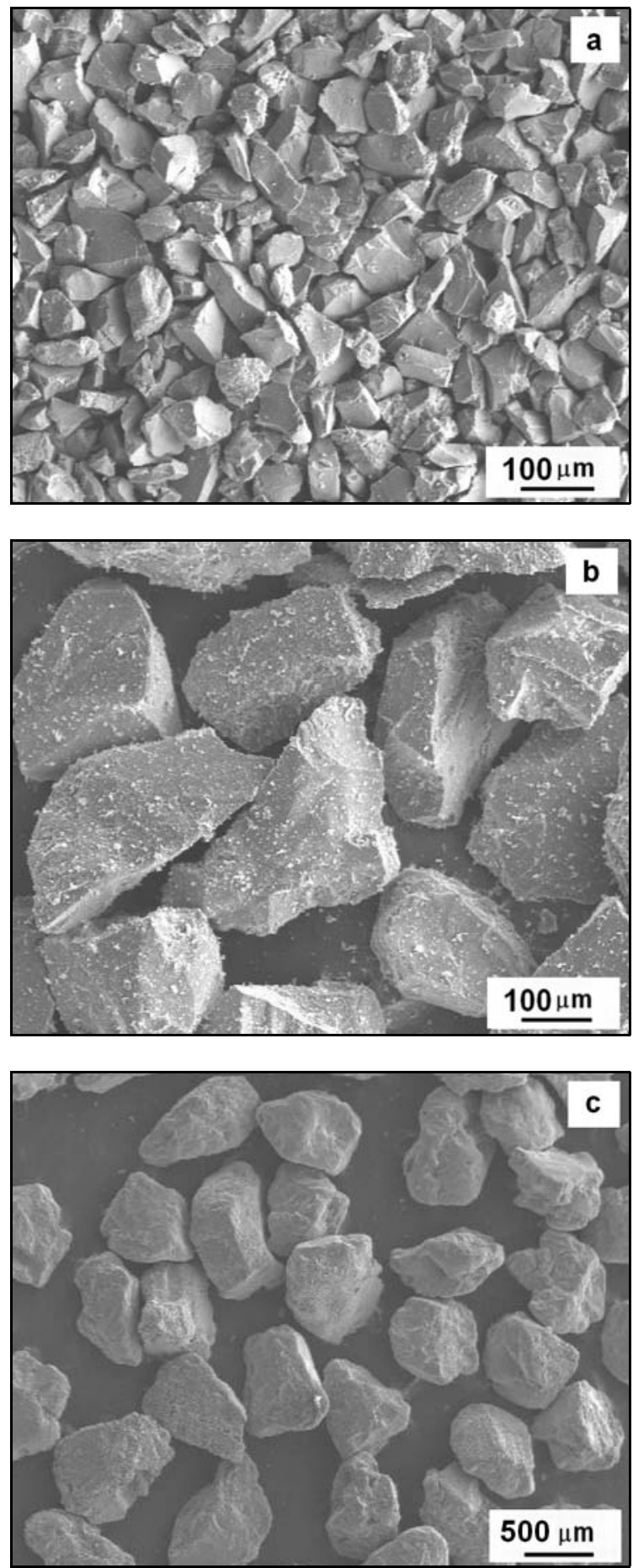

Fig. 5. SEM micrographs of the $\mathrm{SiO}_{2}$ sands surface morphology: a) 60-90 $\mu \mathrm{m}$ grain size, b) $200-300 \mu \mathrm{m}$ grain size, c) $600-700 \mu \mathrm{m}$ grain size.

\subsection{Abrasive sands}

$\mathrm{Al}_{2} \mathrm{O}_{3}$ sand, otherwise corundum or alumina, is specified as a very hard sand with irregular, angular and sharp-edge shape with the hardness on the ninth position of the Mohse hardness scale; it is an 


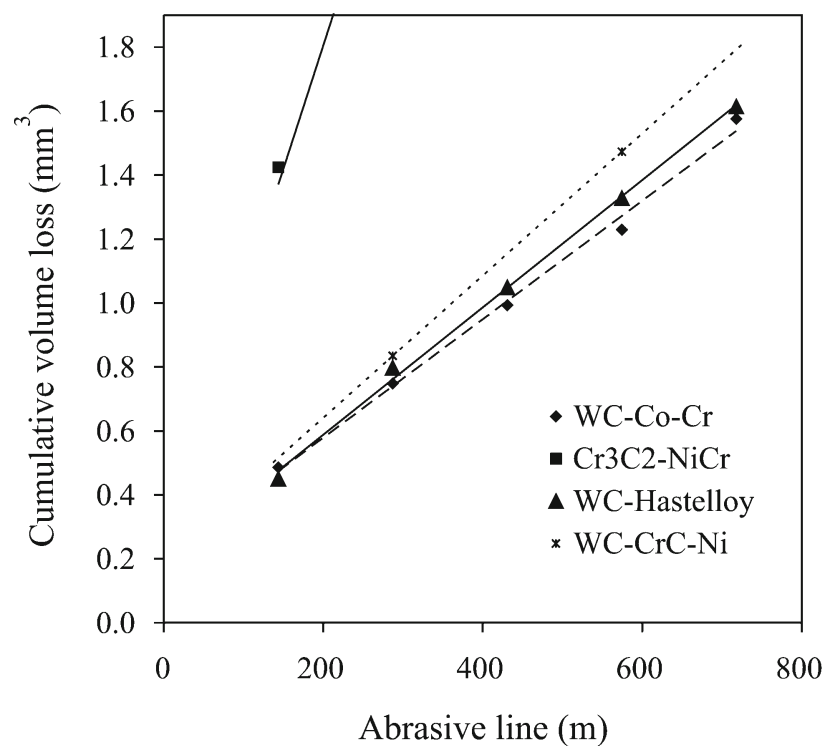

Fig. 6. The comparison of the abrasion wear resistance of WC-Hastelloy coating with other cermet coatings in the test conditions: abrasive line $718 \mathrm{~m}$, load $22 \mathrm{~N}, \mathrm{Al}_{2} \mathrm{O}_{3}$ abrasive sand in $212-250 \mu \mathrm{m}$ grain size.

un-cleavage mineral of a density in the range 4.0-4.1 $\mathrm{g} \mathrm{cm}^{-3}$, which is given by the isomorphic mixture amount and it is ranked among hard minerals with microhardness about $2290 \mathrm{HV}$ [15]. On the other side, the $\mathrm{SiO}_{2}$, otherwise silica sand, is of a lower hardness and it is in the seventh position in the microhardness scale; its microhardness is about $908 \mathrm{HV}$ and its shape is also irregular and sharp-edge but not so markedly like in the $\mathrm{Al}_{2} \mathrm{O}_{3}$ sand; silica oxide exists in four polymorph modifications - silica, tridimit, crystobalit and silica glass; for our abrasion test one of these modifications was used $-\alpha$-silica with the hexagonal crystal lattice of the density $2.53 \mathrm{~g} \mathrm{~cm}^{-3}$ (silica is un-cleavage and is characterized by a conchoidal fracture) [15]. Used abrasive particles are documented in Figs. 4, 5. All the alumina size fractions have similar angular morphologies, whereas the silica has a different shape depending on the particle size. Silica particles of the large size $600-700 \mu \mathrm{m}$ have a slightly rounded shape, whereas the smaller sizes $60-90$ and $200-300 \mu \mathrm{m}$ have more angular morphology.

\subsection{Coatings wear}

Abrasive wear resistance of the WC-Hastelloy coating against $\mathrm{Al}_{2} \mathrm{O}_{3}$ particles of the grain size 212$250 \mu \mathrm{m}$ is shown in Fig. 6. This coating is compared there with conventional WC-Co-Cr, WC-CrC-Ni and $\mathrm{Cr}_{3} \mathrm{C}_{2}$ - $\mathrm{NiCr}$ cermet coatings, which are usually used in the environments of abrasive-corrosive conditions. For $\mathrm{Cr}_{3} \mathrm{C}_{2}-\mathrm{NiCr}$ cermet coating the lowest wear resistance is evident. It is significant that the abrasion wear
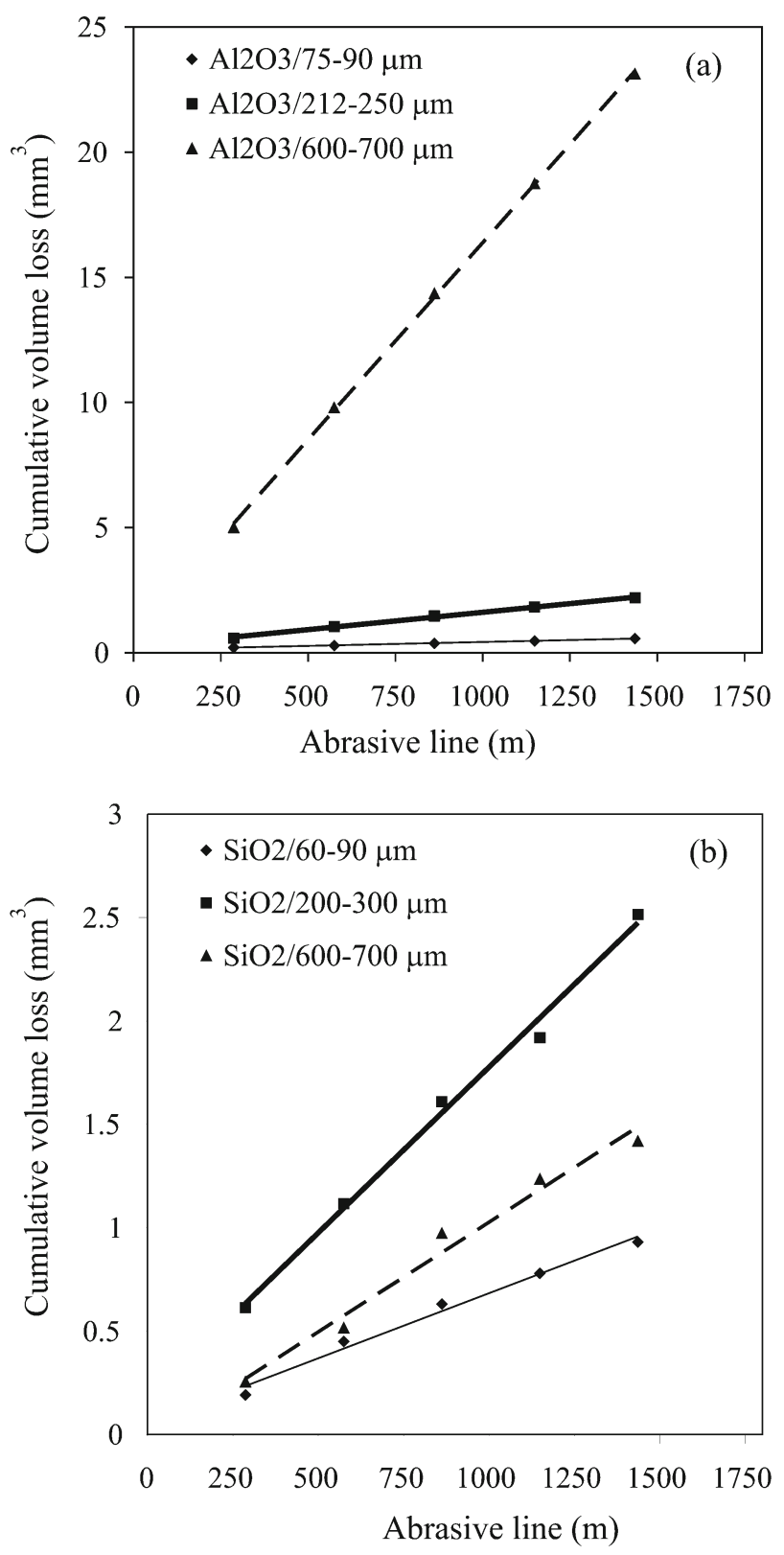

Fig. 7. The influence of abrasive sand type on the abrasive wear of the WC-Hastelloy coating: a) abrading by the $\mathrm{Al}_{2} \mathrm{O}_{3}$ sand in three grain sizes, b) abrading by the $\mathrm{SiO}_{2}$ sand in three grain sizes.

resistance of the WC-Hastelloy is comparable with the traditional WC-Co-Cr cermet coatings. Results show that the WC-Hastelloy coating is a good wear resistant cermet material. The especial ability to resist the wear is caused by the excellent properties common to all cermet coatings, hard phase embedded in ductile alloy/metal matrix, which compensates the carbidegrains brittleness.

Grain size of abrasive particles is a significant factor for wear rate of the coatings material, see Fig. 7. Dissimilar behaviour of different types of abrasive particles was documented for individual abras- 
Table 5. Surface roughness in the wear tracks

\begin{tabular}{ccccccc}
\hline $\begin{array}{c}\text { Surface } \\
\text { roughness }(\mu \mathrm{m})\end{array}$ & \multicolumn{1}{c}{$\begin{array}{c}\mathrm{Al}_{2} \mathrm{O}_{3} \\
600-700 \mu \mathrm{m}\end{array}$} & $\begin{array}{c}\mathrm{Al}_{2} \mathrm{O}_{3} \\
212-250 \mu \mathrm{m}\end{array}$ & $\begin{array}{c}\mathrm{Al}_{2} \mathrm{O}_{3} \\
75-90 \mu \mathrm{m}\end{array}$ & $\begin{array}{c}\mathrm{SiO}_{2} \\
600-700 \mu \mathrm{m}\end{array}$ & $\begin{array}{c}\mathrm{SiO}_{2} \\
200-300 \mu \mathrm{m}\end{array}$ \\
\hline$R_{\mathrm{a}}$ & $2.23 \pm 0.51$ & $1.23 \pm 0.11$ & $0.75 \pm 0.07$ & $0.79 \pm 0.08$ & $0.72 \pm 0.11$ & $1.16 \pm 0.02$ \\
$R_{\mathrm{z}}$ & $11.79 \pm 2.33$ & $6.23 \pm 0.60$ & $4.98 \pm 0.25$ & $3.98 \pm 0.40$ & $4.11 \pm 0.54$ & $7.18 \pm 0.34$ \\
\hline
\end{tabular}

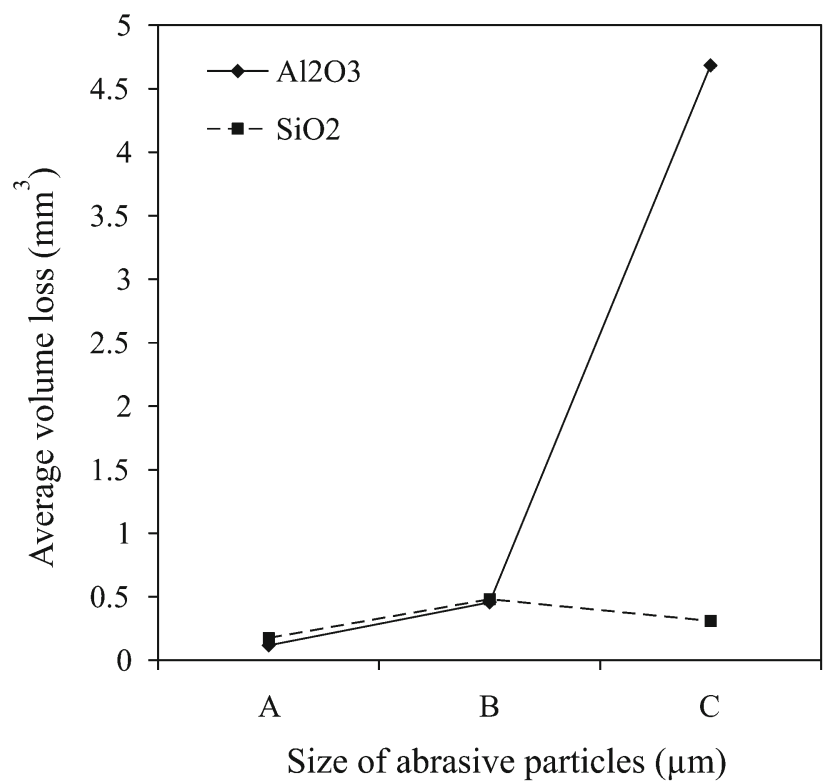

Fig. 8. The comparison of the abrasive abilities of $\mathrm{Al}_{2} \mathrm{O}_{3}$ and $\mathrm{SiO}_{2}$ sands particles to WC-Hastelloy coating, where: $\mathrm{A}-\mathrm{Al}_{2} \mathrm{O}_{3} / 75-90 \mu \mathrm{m}, \mathrm{SiO}_{2} / 60-90 \mu \mathrm{m} ; \mathrm{B}-$ $\mathrm{Al}_{2} \mathrm{O}_{3} / 212-250 \mu \mathrm{m}, \mathrm{SiO}_{2} / 200-300 \mu \mathrm{m} ; \mathrm{C}-\mathrm{Al}_{2} \mathrm{O}_{3} / 600$ $700 \mu \mathrm{m}, \mathrm{SiO}_{2} / 600-700 \mu \mathrm{m}$.

ive grain sizes. For example, cumulative volume loss of tested coatings increases much faster for grain size 600-700 $\mu \mathrm{m} \mathrm{Al} \mathrm{Al}_{2} \mathrm{O}_{3}$ than for two other. The coatings wear increases in sequence of the increasing abrasive grains size. For $\mathrm{SiO}_{2}$ abrasive sands the tendency is not so regular. The highest wear occurs for 200$300 \mu \mathrm{m}$ grain sizes and the lowest for $60-90 \mu \mathrm{m}$ grain size. Supposedly this fact is caused by a different surface morphology of abrasive particles. For better comparison, the WC-Hastelloy ability to resist the different types of abrasive particles (alumina/silica) is shown in Fig. 8.

The abrasive sands in both grain sizes A and B have approximately the same aggressive strength to the coating in spite of their dissimilar properties. However, different behaviour is registered for fraction $\mathrm{C}$. Abrasive ability of $\mathrm{Al}_{2} \mathrm{O}_{3}$ sand is many times higher than that of $\mathrm{SiO}_{2}$ sand. This distinctive contrast could be assigned to lower sharp-edge (angularity) of silica sand in grain size $600-700 \mu \mathrm{m}$, beside its lower microhardness.

\subsection{Wear mechanism of coating}

Wear occurs by the accumulation of damage, fracture and removal of single grains of WC; the basic wear mechanism of all WC-based cermet coatings is the local pulling-out of carbide particles from the binder phase $[7,16,17]$ that succeeded by the creating of free points or holes in the worn surface. Besides this step additional mechanisms described in [16] occur: removal of a binder phase from the surface layer (this loss of binder phase weakens the mechanical strength and structure of the surface layers, leading to increased stressing of the WC grains); plastic deformation and grooving of the binder phase; accumulation of plastic strain in the WC grains; fracture and fragmentation of the individual WC grains and cracking between the WC grains. It is possible to suppose that the wear process could be compared to the process of grinding. During grinding the WC grains are cracked and pulverized by the high-applied stresses of the abrasive grains, part of the carbide grains are pulled-out, leaving some pits, or they are plastically deformed by the compressive stresses in front of the abrasive grains; soft metal binder could be smeared out over the surface with the pulverized WC grains and is partly removed from the surface together with the WC grains and fragments [7].

By the visual control of the WC-Hastelloy worn surface it can be found out markedly dissimilar coatings behaviour. The wear tracks were changing as the types of sands and fraction sizes of the abrasive particles were changed. The wear track caused by alumina 600-700 $\mu \mathrm{m}$ was very large in the length and the wear scratches were very deep and the substrate was exposed. Alumina of 600-700 and 212-250 $\mu \mathrm{m}$ particles grinded the coating surface to a visible gloss, whereas the third sand of alumina together with all the silica sands caused a matt surface in the wear tracks. The wear tracks of the WC-Hastelloy coatings are shown in Fig. 9a-f. It is clearly visible, that $600-$ $700 \mu \mathrm{m} /$ alumina is the most aggressive material. This sand created plenty of extensive scratches in the coating and the considerable plastic deformation and extrusion of binder phase occurred, the coating is greatly ploughed and grooved, Fig. 9a. The next two samples abraded by the alumina of $215-250$ and $75-90 \mu \mathrm{m}$ grain sizes were also ploughed and grooved, but not so significantly. The $75-90 \mu \mathrm{m}$ alumina acted on the 

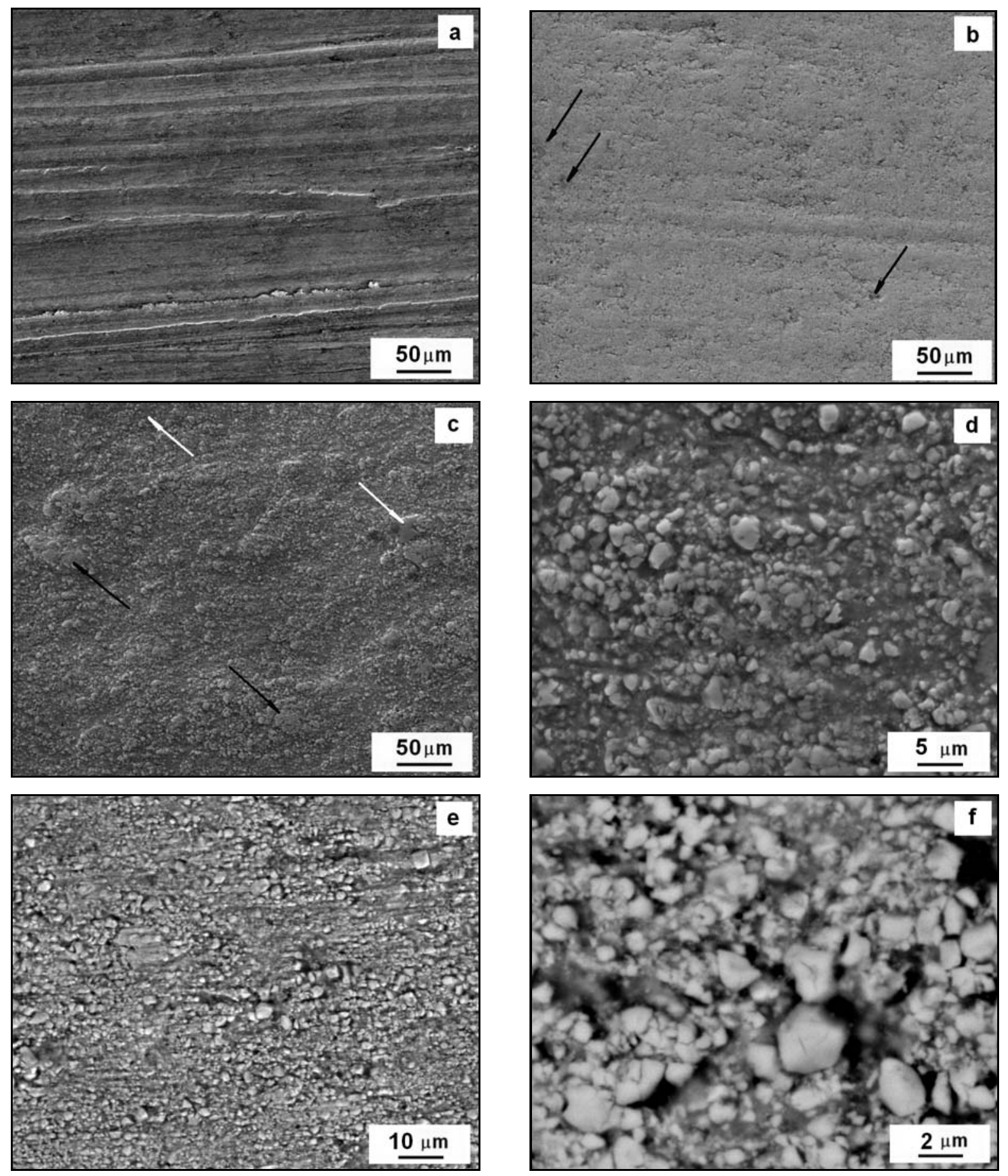

Fig. 9. Micrographs of the worn tracks of the WC-Hastelloy coating, grinding by: a) $\mathrm{Al}_{2} \mathrm{O}_{3}$ 600-700 $\mu \mathrm{m}-$ ploughing and grooving, b) $\mathrm{Al}_{2} \mathrm{O}_{3} 75-90 \mu \mathrm{m}$ - embedding of sand particles, c) $\mathrm{SiO}_{2} 60-90 \mu \mathrm{m}$ - black narrows show the embedding of sand particles and white narrows show embossed materials blocks, d) $\mathrm{SiO}_{2} 60-90 \mu \mathrm{m}-$ surface scouring, e) $\mathrm{SiO}_{2} 200-300 \mu \mathrm{m}-$ smearing of the binder phase, f) $\mathrm{SiO}_{2} 600-700 \mu \mathrm{m}$ - micro-cracks in the WC grains; sliding direction is from left to right.

coatings rather by rolling with compressive stresses incidence, see Fig. 9b; the wear track is against previous two alumina abraded samples very smooth. The smooth surface in the wear track and the rolling mechanism are also observed in the coatings abraded by the silica sand of $200-300$ and $60-90 \mu \mathrm{m}$ grain sizes. In these coatings, the zones of extruded materials blocks were observed, Fig. 9c. For $60-70 \mu \mathrm{m}$ grain sizes of both abrasive sands, the same influence of sands was detected in addition, whole particles or their fragments were cleaved in the wear track, Fig. 9b,c.

In all abraded samples the pulling-out mechanism was observed, but any evident differences in the WC grains pulling-out rate between the investigated 

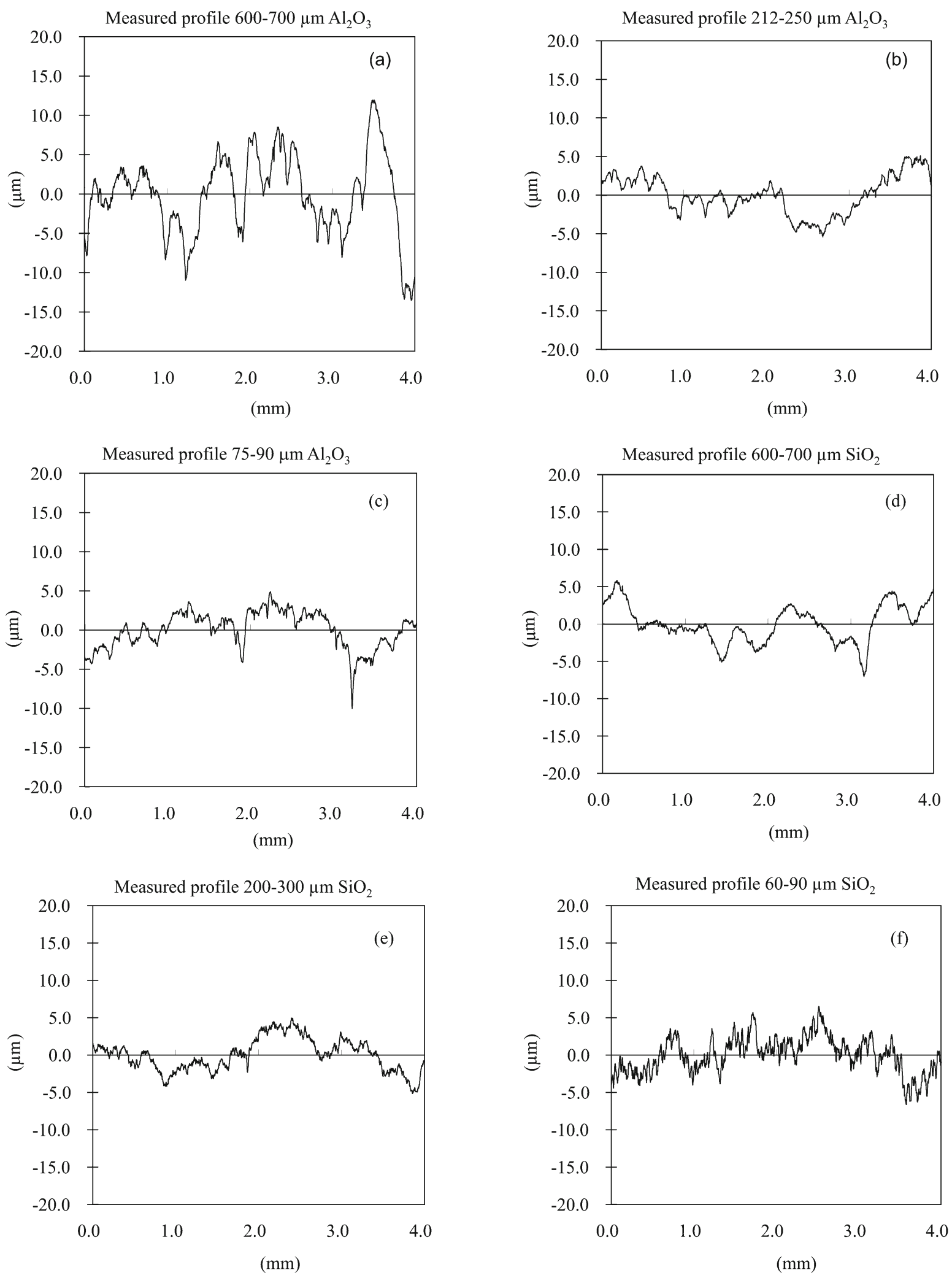

Fig. 10. Measured profiles of WC-Hastelloy wear tracks, across the wear scratch: a) measured profile $600-700 \mu \mathrm{m} \mathrm{Al}_{2} \mathrm{O}_{3}$, b) measured profile $200-250 \mu \mathrm{m} \mathrm{Al} \mathrm{O}_{3}$, c) measured profile $75-90 \mu \mathrm{m} \mathrm{Al}_{2} \mathrm{O}_{3}$, d) measured profile $600-700 \mu \mathrm{m} \mathrm{SiO} 2$, e) measured profile 200-300 $\mu \mathrm{m} \mathrm{SiO}_{2}$, f) measured profile $60-90 \mu \mathrm{m} \mathrm{SiO}_{2}$. 
samples were not found. Table 5 shows the measured values of the surface roughness in the wear tracks. The tracks were measured in the perpendicular direction to the direction of abrasion. From the surface profile it is evident that the wear track caused by alumina 600 $700 \mu \mathrm{m}$ is the coarsest. For the other samples the track roughness is nearly the same and individual values differ only by $0.5 R_{\mathrm{a}}$. The profiles of the wear tracks, Fig. 10a-f, clearly correspond with the tracks morphologies. For alumina $600-700 \mu \mathrm{m}$, the profile is very distinctive and the peaks of heights and valleys are outlaying from the mean line significantly. The other coatings are characterized by the finest profiles in the wear tracks and the heights and valleys inhere near the mean lines. Only for the silica $60-70 \mu \mathrm{m}$, the profile is not so uniform and more distinctive oscillating occurs. That could be the reason of the combination of sands properties: small grain size and lower hardness than the hardness of the WC-cermet. Generally, the particles of sand concentrate on the soft phase and abrade first this binder phase in the midst of the carbides grains. After that the soft binder phase is smearing on the surface and the WC particles remain in the wear track and create a relief of the worn surface with an oscillating waveform in the profile. This does not occur for small particles of alumina $75-90 \mu \mathrm{m}$. The alumina sand is partially able to abrade the WC grains before their pulling-out, due to alumina higher hardness, Fig. 9b, and the worn surface is then very smooth and gloss. For all of silica-abraded coatings the "smearing" and micro grooving occurred. The mechanism of smearing of the binder phase for the silica sand abrading is well marked in Fig. 9e, abrading by $200-300 \mu \mathrm{m}$ silica.

Cracking and crushing of the individual WC grains as in conventional WC-Co coatings, Fig. 9f, characterize the WC-Hastelloy. Fracture and fragmentation of the WC grains for the WC cermets occur as a result of the accumulation of plastic deformation in the $\mathrm{WC}$ grains [16]. In the WC grains the cracks were created predominantly in the perpendicular direction to the direction of abrasion. These cracks are recorded for all coatings regardless of the abrasive sand.

\subsection{Efficiency of abrasive sands}

For the laboratory abrasive wear test evaluation it is necessary to provide the examination of the abrasive particles. In other words, besides wear of the test samples the wear or delamination of abrasive particles occurs during the wear test. The abrasive sands change after using the abrasive properties. Thereupon it is possible to evaluate sands abradability by its periodic using and after that to determine the abrasive efficiency of abrasive medium.

The abrasive efficiency was determined by the application of already used abrasive sands of alumina and silica. The volume loss of two abraded materials was recorded: WC-Hastelloy and carbon steel EN 10025-90. Summary experiments results are given in Fig. 11. For the hard cermet coating the higher wear of abrasive sands than for softer steel material was expected. It is visible that the hard WC-Hastelloy is more aggressive material for $\mathrm{Al}_{2} \mathrm{O}_{3}$ particles than the soft steel bulk. The abrasive ability of the particles in grain sizes $75-90 \mu \mathrm{m}$ and $212-250 \mu \mathrm{m}$ decreased by $40 \%$ after the contact with the WC-Hastelloy, whereas after the contact with the steel material, the abrasion efficiency decreased only by $15 \%$. For the grain size 600-700 $\mu \mathrm{m}$ of $\mathrm{Al}_{2} \mathrm{O}_{3}$ the abrasion efficiency decreased by $20 \%$ for both abraded materials. The abrasive efficiency of the $\mathrm{SiO}_{2}$ particles is to a certain extent different. When the cermet material is taken into account, it is evident that $60-90 \mu \mathrm{m}$ particles did not change their abrasive ability after using. But for grain sizes $200-300 \mu \mathrm{m}$ and $600-700 \mu \mathrm{m}$ the abrasive ability decreased by $20 \%$ and $50 \%$. Results of the silica abrasive ability after carbon steel grinding show that the abrasion efficiency of particles 60-90 $\mu \mathrm{m}$ and 200$300 \mu \mathrm{m}$ decreased by $20 \%$. Silica particles $600-700 \mu \mathrm{m}$ kept their abrasion efficiency after using.

The abrasive efficiency of all $\mathrm{Al}_{2} \mathrm{O}_{3}$ abrasive particles changes in such a way that its steeper decreasing is recorded during grinding the hard material and the more gentle decreasing during grinding the soft steel material. In $[18,19]$ the damage of sand during abrasion test was described. It was shown that the surface of the abrasive sand was severely damaged when used for abrading the hard material. When asperities on the surface of the abrasive sand and the target material are in contact, the probable break-up of the asperities on the sand would result in a decrease in wear of the target material. This predication is closely linked with the decreasing of the abrasive ability of the abrasive particles, because of their sharp asperities breaking. This facticity may happen especially to those target materials having their hardness closer to that of the abrasive sand. In addition, when the asperities on sand are broken, the abrasive sand becomes less angular and this may cause additional decrease in wear. It was also stated that in case of softer grinded material the damage to the sand surface was markedly smaller. These statements were verified by the modelling of the sands surface. However, our results show that behaviour of the softer $\mathrm{SiO}_{2}$ particles is rather casual because not all grain sizes of this abrasive sand lost their abrasive ability during grinding and any dependence between grinding the harder and the softer material occurred. Nevertheless, almost for all the fractions of the abrasive particles (alumina and silica together) it happens to micro smoothing of particles angularity, Fig. 12, and the particles are more or less losing their high abrasive ability and their abrasive efficiency decreases. The abrasive efficiency 


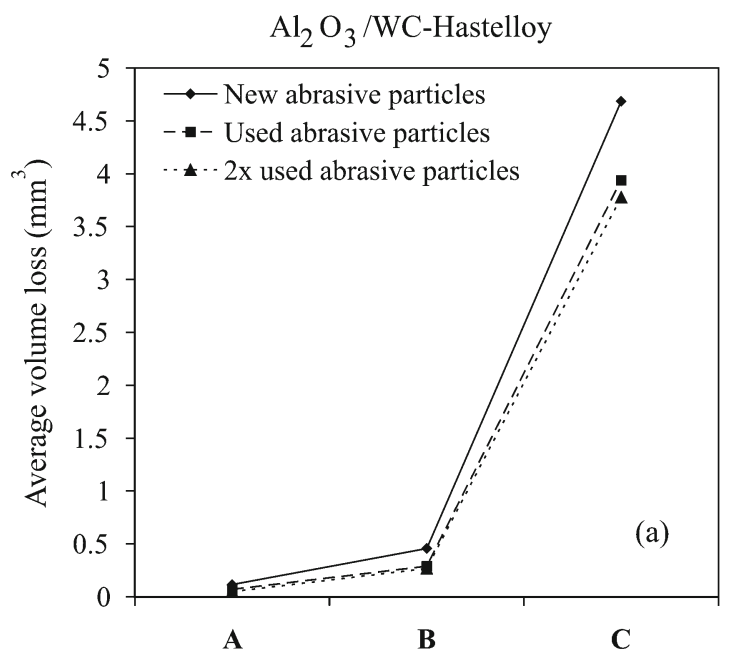

Size of abrasive particles $(\mu \mathrm{m})$

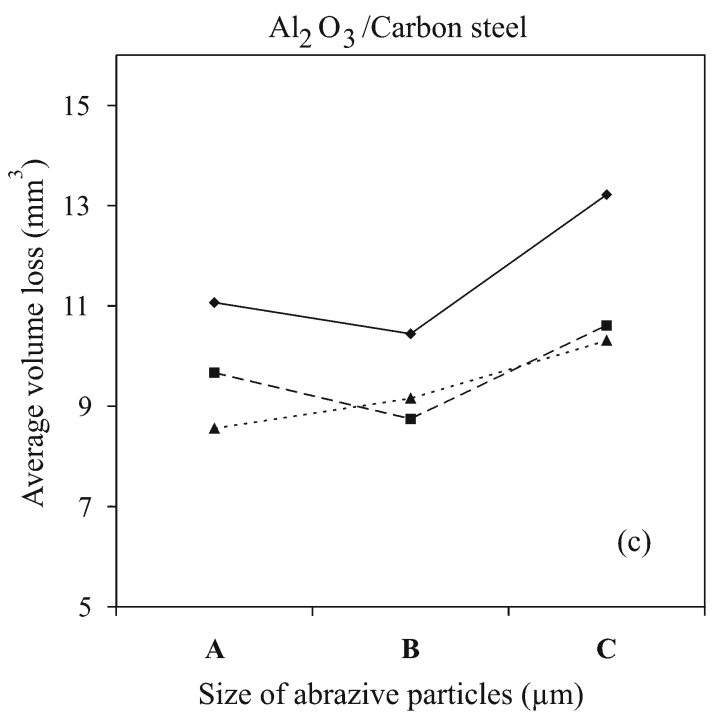

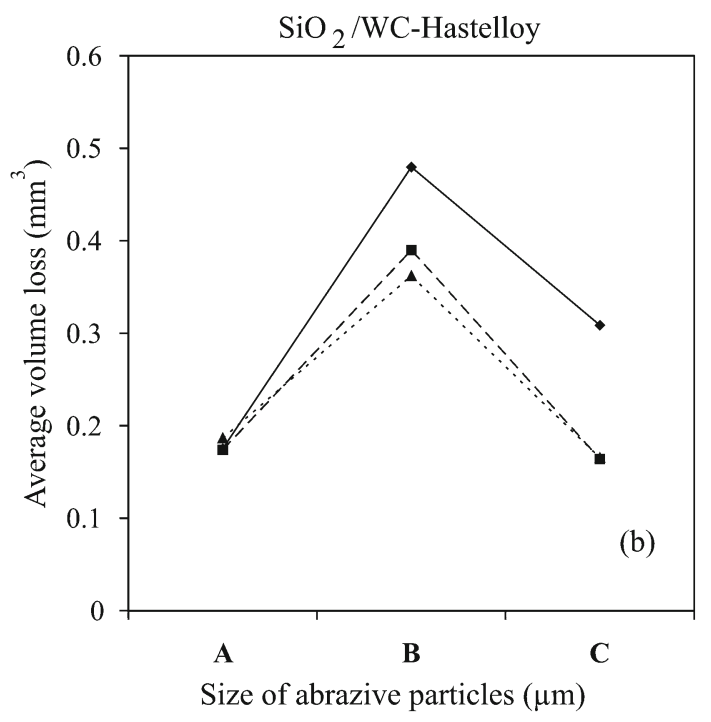

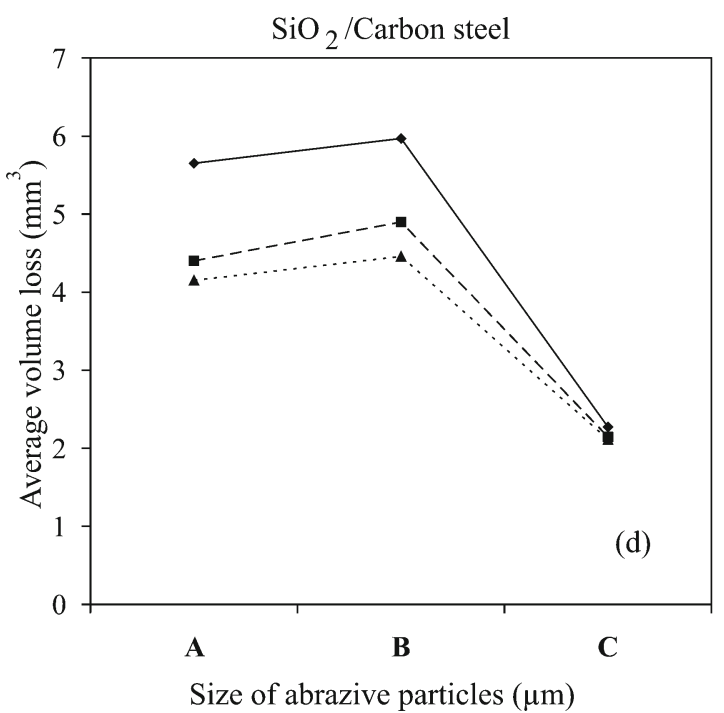

Fig. 11. Abrasive efficiency of $\mathrm{Al}_{2} \mathrm{O}_{3}$ and $\mathrm{SiO}_{2}$ sands in dependence on the sand grains sizes and the abraded materials, where: $\mathrm{A}-\mathrm{Al}_{2} \mathrm{O}_{3} / 75-90 \mu \mathrm{m}, \mathrm{SiO}_{2} / 60-90 \mu \mathrm{m} ; \mathrm{B}-\mathrm{Al}_{2} \mathrm{O}_{3} / 212-250 \mu \mathrm{m}, \mathrm{SiO}_{2} / 200-300 \mu \mathrm{m} ; \mathrm{C}-\mathrm{Al}_{2} \mathrm{O}_{3} / 600-700 \mu \mathrm{m}$, $\mathrm{SiO}_{2} / 600-700 \mu \mathrm{m}$; a) $\mathrm{Al}_{2} \mathrm{O}_{3}$ sands after abrading WC-Hastelloy coating, b) $\mathrm{SiO}_{2}$ sands after abrading WC-Hastelloy coating, c) $\mathrm{Al}_{2} \mathrm{O}_{3}$ sands after abrading carbon steel, d) $\mathrm{SiO}_{2}$ sands after abrading carbon steel.

decreases most of all in the first contact with the material. It is evident that the abrasive particles loose their efficiency with their first using and further using has no effect on their abrasive efficiency. To the determination of changes in abrasives morphologies a scanning electron microscope (SEM) was used. In the SEM micrographs of $\mathrm{Al}_{2} \mathrm{O}_{3}$ and $\mathrm{SiO}_{2}$ sand particles no significant changes in the shape and size or particles fracture were observed. That is caused mainly due to low-stress abrasive condition, respectively due to a relatively low samples loading and low sliding speed. These two test parameters are critical factors for major and visible damage of abrasive sand particles [18, 19]: high load and high sliding speed leads to surface failure that is distinguished by no facets appearance compared to the original sand surface. It must be mentioned that the damaged sand particles were collected using a container placed below the tester. The collected sand might be more or less mixed with some fresh sand particles, which did not go through the gap between the rubber wheel and the specimen. Therefore the information about surface morphologies of the abrasive particles could be slightly misleading. However, the nozzle was so close to the gap that most sand particles could go through it.

\section{Conclusions}

The main purpose of this study was to find the 


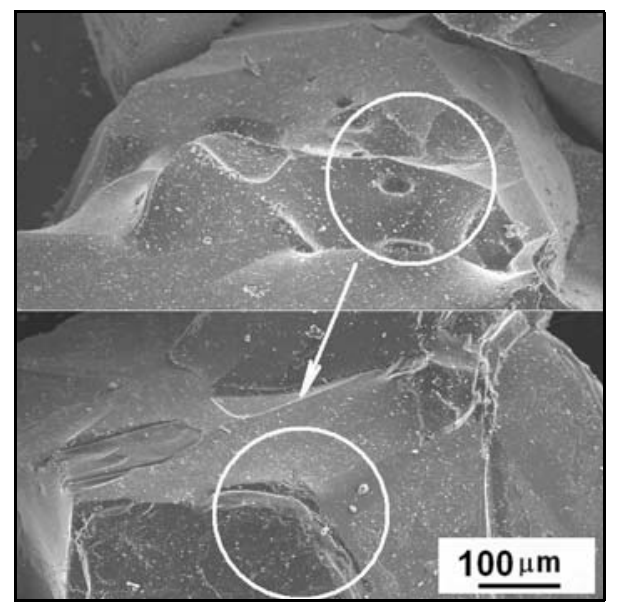

Fig. 12. The change of the surface conditions of the particle of $\mathrm{Al}_{2} \mathrm{O}_{3}$ sand of $600-700 \mu \mathrm{m}$ grain size: micro-rounding of the particles edges.

differences between various abrasive sands, to evaluate the influence of different abrasive sands on the wear of cermet coating and to detect the abrasive efficiency of sands during Dry Sand/Rubber Wheel test. DSRW test is widely used in industry for the help to detach and evaluate wear-resistant coatings. The abrasion test is often performed under a fixed load, fixed sliding speed and one kind of abrasive particles is used to obtain all materials evaluated under the same conditions. This study was aimed the attention to the variations in the abrasive sand under three-body abrasion and low-stress condition. It was found that the abrasive resistance of superior corrosive resistant WC-NiMoCrFeCo coating is comparable with the conventional cermet coating generally used as abrasive protectors in corrosion surroundings. The WC-Hastelloy was abraded by two types of abrasive sand (alumina and silica) in three different grain sizes. It was unsurprising that alumina was more aggressive abrasive medium to the cermet coating than silica. For alumina sand it was detected that the highest volume loss of the cermet material was caused by large particles more than by the smaller ones. The main wear mechanism of WC-Hastelloy coating caused by alumina particles was grooving, ploughing and cutting of the surface. The wear resistance of the WC-Hastelloy coating tested by silica showed other trend. The highest volume loss of the cermet material was caused by $200-300 \mu \mathrm{m}$ particles grain size, then 600 $900 \mu \mathrm{m}$ and at last $60-90 \mu \mathrm{m}$. This fact was attributed to different silica angularity between its grain sizes. The dependence of the coating volume loss was attributed to the particles angularity and shape more than to their size. The main wear mechanism of silica particles was smearing of the binder phase and extruding of large materials blocks in the wear track. For $60-70 \mu \mathrm{m}$ grain sizes of both abrasive sands, the same property was found: whole sands particles and their fragments were cleaved in the wear track and they were fixated in the matrix phase between the carbide grains.

Abrasion efficiency of both abrasive sands was investigated by their periodical using. Besides the hard WC-Hastelloy also the soft carbon steel material was abraded. It was found that the abrasive efficiency of alumina and silica significantly decreased no matter which of surface hardness the abrading material possessed. Only for alumina sand, greater sensitivity was detected to abrading the hard material, thereupon the abrasive efficiency decreased more remarkably than by abrading the soft carbon steel. The SEM micrographs of surface morphology of sand particles did not show obvious changes after their using. The loss of abrasive efficiency was caused only by micro-smoothing of particles angularity and the "low-stress" abrasive conditions of DSRW measurement caused no visible defects such as crushing or fracture of the abrasive particles. Further it was found that in "low-stress" conditions the abrasive efficiency decreased only by the first use of the particles and by their following use the efficiency stayed almost identical.

\section{Acknowledgements}

The work was supported by the Grant Agency of the Academy of Science of the Czech Republic under the CV 1QS200430560 project.

\section{References}

[1] ASTM G65-00 ${ }^{\varepsilon 1}$, Standard Test Method for Measuring Abrasion Using the Dry Sand/Rubber Wheel Apparatus, PA 19428-2959, United States 2001.

[2] BHUSHAN, B.: Introduction to Tribology. New York, John Wiley \& Sons 2002.

[3] AVERY, H. S.: In: Proceedings of International Conference on Wear of Materials. Eds.: Glaeser, W. A., Ludema, K. C., Thee, S. K. New York, ASME 1977, p. 148.

[4] HAWK, J. A.-WILSON, R. D.-TYLCZAK, J. H.Dogan, O. N.: Wear, 225-229, 1999, p. 1031.

[5] PIKE, L. M., Jr.: Age-hardenable, Corrosion Resistant Ni-Cr-Mo Alloys, United States Patent US 6,860,948 B1, USA 2005.

[6] AMPERIT ${ }^{\circledR} 529$ WC-NiMoCrFeCo 85/15 Agglomerated Sintered, Product Information, H. C. Starck, Goslar 2008.

[7] HEGEMAN, J. B. J. W.-DE HOSSON, J. TH. M.DE WITH, G.: Wear, 248, 2001, p. 187.

[8] SCHWETZKE, R.-KREYE, H.: Journal of Thermal Spray Technology, 8, 1999, p. 433.

[9] JACOBS, L.-HYLAND, M. M.-DE BONTE, M.: Journal of Thermal Spray Technology, 8, 1999, p. 125.

[10] GUILEMANY, J. M.-DOSTA, S.-NIN, J.-MIGUEL, J. R.: Journal of Thermal Spray Technology, 14, 2005, p. 405. 
[11] BERGER, L.-M.-ETTMAYER, P.-VUORISTO, P.-MANTYLA, T.-KUNERT, W.: Journal of Thermal Spray Technology, 10 , 2001, p. 311.

[12] BERGET, J.-RONGE, T.: In: Proceedings of the International Thermal Spray Conference, ITSC 2001. Eds.: Berndt, C., Khor, K. A., Lugscheider, E. F. ASM International, Material Park 2001, p. 1157.

[13] HENKE, H.-ADAM, D.-KOHLER, A.-HEIMANN, R. B.: Wear, 256, 2004, p. 81.

[14] BERGET, J.-RONGE, T.: In: Proceedings of the International Thermal Spray Conference, ITSC 2004. Eds.: Kuroda, S. et al. Dusseldorf, DVS - German Welding Society 2004.
[15] VOCEL, M.-DUFEK, V. et al.: Tření a opotřebení strojních součástí. Prague, Technical Literature SNTL 1976.

[16] GEE, M. G.-GANT, A.-ROEBUCK, B.: Wear, 263, 2007, p. 137.

[17] QIAO, Y.-LIU, Y.-FISCHER, T. E.: Journal of Thermal Spray Technology, 10, 2001, p. 118.

[18] MA, X.-LIU, R.-LI, D. Y.: Wear, 241, 2000, p. 79.

[19] ELALEM, K.-LI, D. Y.: Wear, 250, 2001, p. 59. 